JGG 2022;70:68-82

doi: $10.36150 / 2499-6564-N 415$

\title{
Age discrimination in delivery of health services to old people during COVID-19 pandemic: a scoping review study
}

\author{
Seyede Shahrbanoo Daniali', Majid Rahimi², Shahin Salarvand ${ }^{3}$ \\ ${ }^{1}$ Health Education and Health Promotion. Child Growth and Development Research Center, \\ Research Institute for Primordial Prevention of Non-Communicable Disease, Isfahan University of \\ Medical Sciences, Isfahan, Iran: ${ }^{2}$ Department of Health Education and Promotion, School of Health, \\ Isfahan University of Medical Sciences, Isfahan, Iran; ${ }^{3}$ Department of Nursing, School of Nursing \\ and Midwifary, Lorestan University of Medical Sciences, Khorramabad, Iran
}

Received: June 27, 2021

Accepted: August 26, 2021

\section{Correspondence \\ Majid Rahimi \\ Department of Health Education and Promotion, School of Health, Isfahan University of Medical Sciences, Hezar-Jarib Street, Azadi Square, Isfahan, 81746-73461 Iran \\ E-mail: majidnh79@gmail.com}

How to cite this article: Daniali SS, Rahimi M, Salarvand S. Age discrimination in delivery of health services to old people during COVID-19 pandemic: a scoping review study. Journal of Gerontology and Geriatrics 2022;70:68-82. https://doi. org/10.36150/2499-6564-N415

(C) Copyright by Società Italiana

di Gerontologia e Geriatria (SIGG)

\section{(c) (1) $(9)$}

\section{OPEN ACCESS}

This is an open access article distributed in accordance with the CC-BY-NC-ND (Creative Commons Attribution-NonCommercial-NoDerivatives 4.0 International) license. The article can be used by giving appropriate credit and mentioning the license, but only for non-commercial purposes and only in the original version. For further information: https://creativecommons.org/licenses/by-nc-nd/4.0/deed.en
Background \& objectives. Age discrimination causes many consequences and complications in old people as a high-risk group. With the outbreak of the COVID-19 pandemic, delivery of care and treatment services to old people has become a major challenge. The present study aimed to synthesize and summarize the conditions of discrimination in the delivery of health services to old people during the COVID-19 pandemic.

Research design \& methods. A scoping review was performed using Arkesy and O'Malley's framework. PUBMED, Scopus, Web of Science, Embase, ProQuest, Science direct, SPRINGER, and Wiley databases were searched using the related keywords. Out of 246 retrieved studies, 21 published studies related to ageism toward old people in the delivery of healthcare services to old people during the COVID-19 pandemic were examined.

Results. Most of the published reports were from European countries and the United States. Although they indicated a growing trend of anti-aging attitudes, there were some positive behaviors toward them. Promotion of anti-aging culture, discriminatory guidelines and decisions and feeling of insignificance by the old people themselves may be associated with the condition of discrimination against them.

Discussion \& implications. The articles were related to limited countries. Owing to discriminatory behaviors in the delivery of health services to old people, it is necessary for health policy-makers to develop protocols on the delivery of healthcare services to this group transparently to minimize harm, enhance positive behaviors toward this group, and train healthcare providers and old people.

Key words: COVID-19, age discrimination, old people, healthcare, delivery of healthcare

\section{BACKGROUND AND OBJECTIVES}

The outbreak of the COVID-19 pandemic has imposed a substantial burden of mortality and morbidity on the healthcare system of countries ${ }^{1}$. In July 2021, the WHO reported 196,553.009 confirmed cases of COVID-19, including 4,200.412 deaths ${ }^{2}$. Among various age groups, old people with COVID-19 have shown more severe symptoms ${ }^{3-5}$. In addition, since 
aging is associated with chronic diseases, the risk of death in these people is affected by COVID-19 ${ }^{6}$. An upward trend of the probability of death in the old people with COVID-19 aging has been shown; the rate of mortality in the sixties, seventies and eighties has been demonstrated to be 3.6, 8.8 and $14.8 \%$, respectively ${ }^{3}$. Statistics suggested that more than $90 \%$ of deaths during the COVID-19 pandemic occurred in people over 60 years old and more than $50 \%$ of them occurred in people over 80 years old ${ }^{7}$. The nursing home residents also account for more than half of all COVID-19-related deaths worldwide ${ }^{1}$. The high rates of morbidity in this age group may be rooted in caring behaviors ${ }^{8}$.

The high rates of morbidity in this age group may be rooted in caring behaviors, so that an association between care-elder-friendly approaches and fewer falls, less functional decline, shorter length of hospital stay, in comparison to traditional care $^{9}$, has been established. In addition, elder mistreatment was associated with an increased mortality rate in old adults ${ }^{10}$.

One characteristic of public health crises is the shortage of medical facilities. Difficult decisions must be made about who should use the limited facilities, and how and where they should be used ${ }^{11}$. Appropriate support measures have been taken for the old people over 70 years old during the COVID-19 pandemic ${ }^{12}$. However, how intensive care unit facilities are allocated to older patients shows the deprivation of many of them. Therefore, due to the shortage of ventilators, only some patients can receive them in critical situations ${ }^{13}$. In this regard, some guidelines have been proposed on how these resources are used by medical associations ${ }^{14}$, which may lead to the prevalence of behaviors related to age discrimination ${ }^{15}$. Age discrimination is common in the community and daily lives of old people. Such discriminations have always threatened the lives of the old people. The absence of the old people in the cycle of wealth production and heir weak physical conditions have endangered the delivery of health services to them ${ }^{16}$.

In one study, 35\% of people over 52 years of age in the United Kingdom and 29\% in the United States reported several experiences of discriminatory behaviors. In another study, only $11 \%$ did not experience any discriminatory behaviors ${ }^{17}$. This issue leads to inequality in receiving health services ${ }^{18}$. Age discrimination was also seen among healthcare staff in the delivery of health services before the COVID-19 pandemic ${ }^{19-21}$. Age discrimination has many effects on old people's physical, mental and social well-being, resulting in reduced life expectancy, social isolation, and reduced adherence to preventive health behaviors ${ }^{20,22}$. As mentioned above, the outbreak of the COVID-19 pandemic has imposed a significant burden on healthcare systems, leading to a severe shortage of resources needed to solve patients' problems, thereby prioritizing people to receive medical services, particularly acute care, intensive care unit, and ventilator services ${ }^{23,24}$.

The current beliefs about old people have caused young people to be prioritized in receiving medical facilities, such as mechanical ventilator ${ }^{3}$; however, guidelines recommend that decisions on the use of medical equipment should be made based on the patient's physical conditions, not their age ${ }^{25}$. Several reports due to the increased risk of COVID-19 disease among older people have made them to stay at home ${ }^{26}$. Moreover, the unpleasant and shocking news of caring for old people during the COVID-19 pandemic has been reported from March 2020 to May $2020{ }^{26}$. Age discrimination against old people can be observed at both individual and structural levels ${ }^{18}$. The stereotype embodiment theory (SET) represents three different but interrelated types of age discrimination: practical age discrimination reflecting harmful behaviors against old people, age-related negative stereotypes reflecting individuals' beliefs about old people, and self-perception in the second adulthood reflecting old people's opinions about their aging. Based on this theory, three types of age discrimination have harmful effects on old people's health by affecting their psychological, behavioral and physical dimensions ${ }^{27}$. Considering the outbreak of the COVID-19 pandemic, the evidence for the occurrence of age discrimination in the delivery of health services worldwide, and its significant effects on various aspects of their health, it is essential to conduct a systemic review of studies on the delivery of healthcare services to old people during the COVID-19 pandemic.

It is noteworthy that this pandemic is a new phenomenon; therefore, there are a limited number of articles on this issue. However, given the importance of this issue, the results of these studies can be useful for the health system to avoid similar cases in our community by observing the evidence for the consequences of age discrimination. In addition, searches on valid sites to find further studies will be continued. Several reports of discrimination against old people, especially during the COVID-19 outbreak, led us to conduct a study aiming at explaining different conditions of discrimination against old people in the healthcare system during the COVID-19 pandemic.

\section{RESEARCH DESIGN AND METHODS}

In the present study, the scoping Review method was used to create a systematic map of existing studies on age discrimination in the delivery of health services to old people during the COVID-19 pandemic. The 
PRISMA checklist was also used to report the results (see Supplementary Material). The scoping review was performed using Arkesy and O'Malley's framework ${ }^{28}$. This framework includes the following steps.

\section{IDENTIFICATION OF THE RESEARCH QUESTION}

Consulting with the research team, the desired concepts and the study population were identified, and then the main research questions were determined:

1. What are the conditions of discrimination in the delivery of health services to old people during COVID-19 disease?

\section{IDENTIFYING RELEVANT STUDIES}

In coordination with the research team, related databases were used to find the relevant articles and appropriate search strategies for the research topic. All the considered articles were published in 2020. Since they have not referred to the causes of discrimination, this study examined the causes of discrimination in the delivery of health services to old people during COVID-19 disease.

\section{Search Strategy}

Databases used to extract related articles in this research included PUB MED, Scopus, Web of Science, Embase, Proquest, Sciencedirect, SPRINGER, and Wiley. It was attempted to select those databases, including most terms related to the research topic. To search relevant articles, MeSH terms and other related words including "Old people", "Ageism", "Age Discrimination", "Age Discriminations", "Discrimination", "Age", "COVID-19", and "Delivery of Healthcare", were used with and without quotation marks using the Boolean operators of "and" and "or". Moreover, "*" star was used to expand the search if needed. The considered period was set from the beginning of 2020 when the global outbreak of COVID-19 started to November 1 , 2020. The articles were evaluated in English.

\section{Selection of studies}

\section{Eligibility criteria and study selection}

The eligibility criteria were being related to the age discrimination of old people (over 60 years of age), being related to the delivery of health services during the COVID-19 pandemic, being in English, and being accepted or published. Studies including letters to the editor, professor protocol, and unrelated results, and all dissertations and theses were excluded.

\section{ASSESSMENT OF RISK OF BIAS}

Among two similar studies, one of which was a gray article and another one was a peer review, the gray article was removed. The articles were first assessed in terms of the relevance of the title and abstract by two reviewers. If there was a disagreement between them about the inclusion of an article in the study, to avoid the risk of bias, the final agreement would be reached first through discussion and in some cases according to the third reviewer's opinion. Next, the full texts of all studies included were retrieved and using the WEIRD (Ways of Evaluating Important and Relevant Data) tool [29], (see Supplementary Material), which is used for crosssectional studies, their quality was assessed, and the approved articles were entered into the study (Table 1). Then, the required data were extracted from qualified articles and recorded in the Excel software. The data included study country, year, and type of study. Based on the search process, 246 articles were extracted and after removing 35 duplicates, 211 articles were entered into the study. After the initial review by two reviewers, 102 articles were excluded. Articles including letters to the editor, unrelated contents to the age discrimination in the delivery of health services to old people, and duplicate titles were excluded. Finally, 21 articles were entered into the study (Fig. 1). Included studies were on topics, such as conditions of discriminatory decisions,

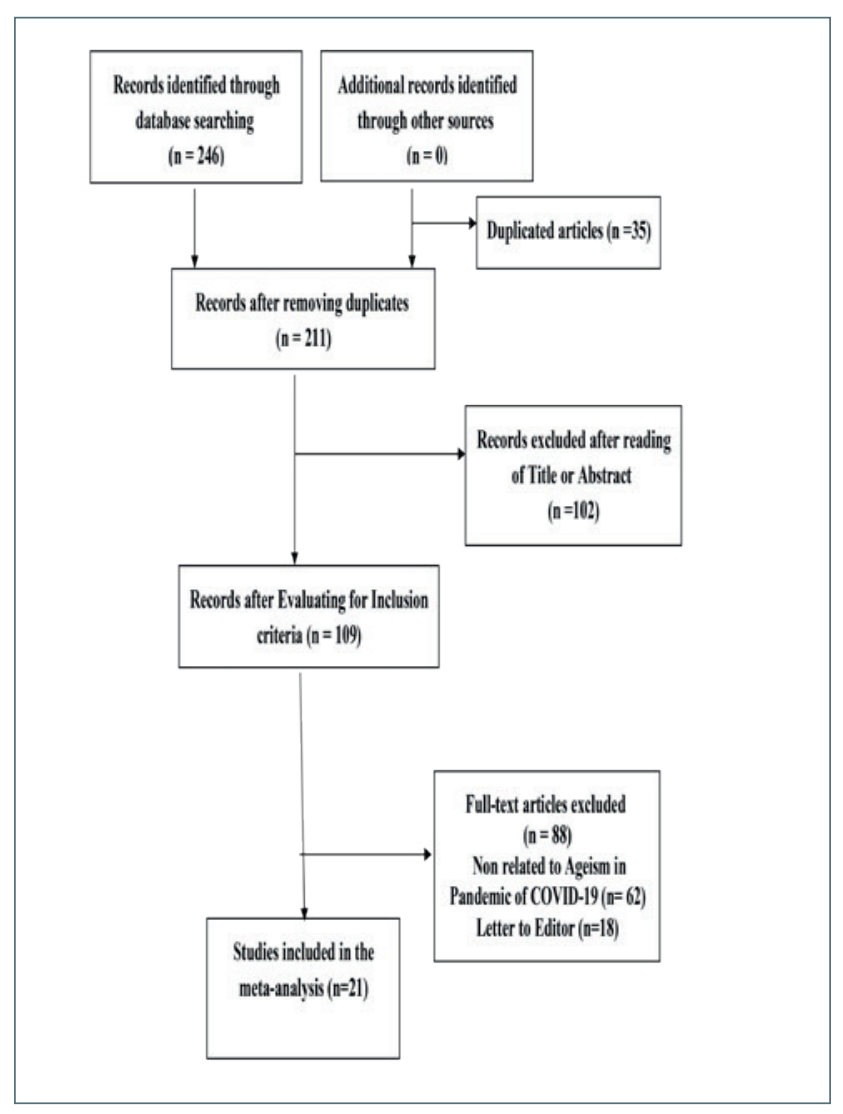

Figure 1- Flowchart of article selection. 
shortcomings leading to such decisions, anti-aging culture, and positive aspects of protocols and laws related to the delivery of healthcare to old people during the COVID-19 pandemic.

\section{Charting the DATA}

The data of included articles were examined and extracted independently by two reviewers. A table was designed to list the information of the articles in it. The information was as follows (Tab. II):

- title;

- country of study;

- the key points of the study.

First, five articles reviewed by reviewers were compared in terms of stability of the information extracted. All of the articles included in the present study were descriptive and written merely based on the observations and available documents.

\section{Collation, summarization AND REPORT OF RESUltS}

The results were extracted based on the topics and classified thematically. These themes were evaluated and approved by two independent reviewers. At this stage, with the consent of two reviewers, the disagreements were resolved by the third reviewer. The results were divided into individual and social themes, including anti-aging culture, discriminatory protocols, feelings of insignificance by old people themselves, and positive cases. The included articles covered at least one of the extracted themes. The extracted data were initially summarized as key points based on themes. The articles included in the study covered the aim of the study, which was to determine the types and causes of age discrimination. Finally, some recommendations were provided to health policymakers on effective measures to prevent ageism against old people during the COVID-19 pandemic. After obtaining permission from Isfahan University of Medical Sciences, this study was conducted with Ethical Code No. IR.MUI.RESEARCH. REC.1399.147 and Research Proposal No. 199106 by the financial support of the same university.

\section{RESULTS}

In this section, the identified causes of age discrimination are discussed. A review of the studies shows that they were conducted in various countries, such as Italy, China, USA, Switzerland, Spain, Bangladesh, Belgium, Poland, and France. According to them, the most cases of discrimination against old people were found in Italy, Spain and the United States, and the most protective measures were reported in Germany ${ }^{30}$. Moreover, there were no formal cases in Belgium, Poland, France and the United Kingdom ${ }^{31}$. However, protective laws were enacted in all countries, including the United States ${ }^{2}$.

\section{Promotion of ANTI-AgIng CULtURE}

Expansion of the anti-aging culture in its various dimensions, especially in receiving health services, has been considered for many years ${ }^{18}$. The present study also addresses the various dimensions of the anti-aging culture. This aspect of age discrimination reflects the discriminatory structure in society formed by the governing system, including local governments in Spain. Such a structure prevents the delivery of health services to old people and promotes injustice against them ${ }^{32}$. For example, one can mention a television program promoting the preference for sacrificing old people to save the young in Texas, the United States ${ }^{33}$ as a practical example of this culture. The expectation of society from old people to be sacrificed for the sake of the country's economy is a significant issue in this regard, which was raised due to the creation of a generation called the COVID-19 generation ${ }^{34,35}$.

The insistence of society and staff on triaging old people on their arrival in the emergency department is one of the factors reflecting the existing culture of eliminating or ignoring old people in the delivery of health services, in addition to the existing guidelines in the Corona crisis ${ }^{3}$. In the Catalonia region, nursing home old people residents with a suspected or definitive diagnosis of COVID-19 and other underlying diseases were prohibited to refer to health centers. In addition, personal protective equipment was not provided for them, and they encountered staff shortage ${ }^{31}$. Studies have indicated that not paying serious attention to the health of old people has caused complications of the disease in them ${ }^{7}$. This discriminatory attitude has a negative impact on the health of old people and the whole health system ${ }^{36}$. Age discrimination against old people before COVID-19 ${ }^{6}$ and hiding discriminatory behaviors are also examples of the anti-aging culture in the delivery of health services to old people ${ }^{25}$.

\section{DISCRIMINATORY GUIDELINES AND DECISIONS}

Several articles have referred to the allocation of medical facilities to old people and discriminatory measures. For example, one can mention the priority of medical staff to receive medical services as a discriminatory measure ${ }^{13,37}$. The following are the examples of guidelines for the delivery of health services to COVID-19 patients during the disease outbreak: exclusion of patients with underlying diseases from the list of services ${ }^{9}$; decision on who should receive services, old people or young, with or without underlying diseases, medical staffs or other people ${ }^{38}$; allocation of resources to those with a higher chance of survival, determination of a given age $^{4}$ to use the facilities and then reduction of it from 


\begin{tabular}{|c|c|c|c|c|c|c|c|c|c|c|c|}
\hline 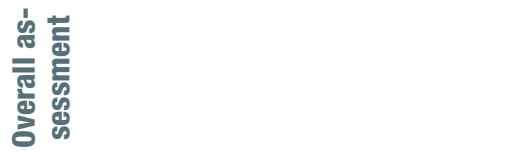 & 号 $\frac{\bar{\nu}}{\mathrm{d}}$ & 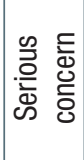 & 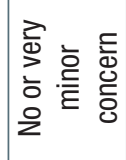 & 竞 & 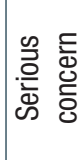 & 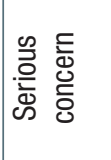 & 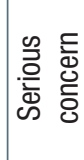 & 을 & 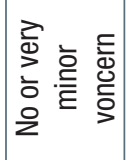 & 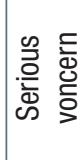 & 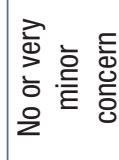 \\
\hline 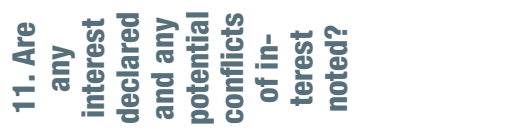 & $>$ & $z$ & $\supset$ & $>$ & $z$ & $>$ & $>$ & $z$ & $>$ & $z$ & $\supset$ \\
\hline 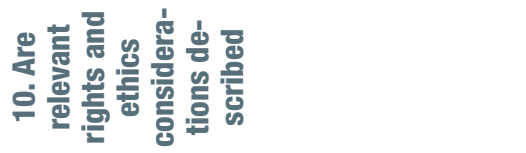 & $z$ & $>$ & $>$ & $>$ & $>$ & $>$ & $\supset$ & $>$ & $>$ & $>$ & $>$ \\
\hline 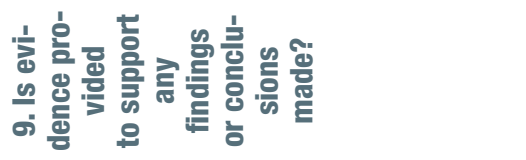 & $>$ & $\supset$ & $>$ & $\supset$ & $>$ & $>$ & $\supset$ & 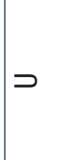 & $>$ & 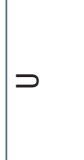 & $>$ \\
\hline 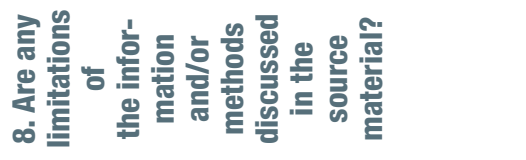 & $>$ & $z$ & $\supset$ & $z$ & $z$ & $z$ & $z$ & $z$ & $>$ & $>$ & $>$ \\
\hline 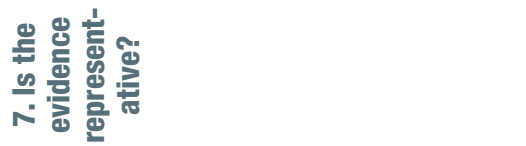 & $>$ & $z$ & $>$ & $\supset$ & $\supset$ & $\supset$ & $\supset$ & $z$ & $\supset$ & $\supset$ & $>$ \\
\hline 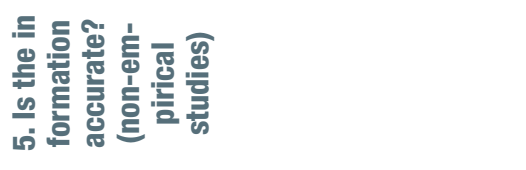 & $>$ & $>$ & $>$ & $>$ & $>$ & $>$ & $>$ & $>$ & $>$ & $>$ & $\supset$ \\
\hline 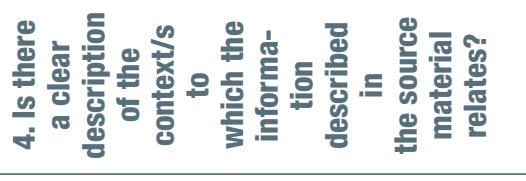 & $>$ & $>$ & $>$ & $>$ & $>$ & $>$ & $>$ & $>$ & $>$ & $>$ & $>$ \\
\hline 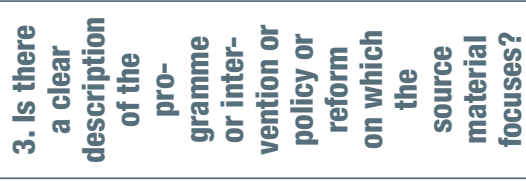 & $\supset$ & $>$ & $>$ & $>$ & $>$ & $>$ & $>$ & $>$ & $>$ & $>$ & $>$ \\
\hline 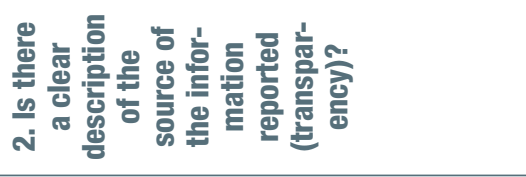 & $>$ & $>$ & $>$ & $>$ & $>$ & $>$ & $>$ & $>$ & $>$ & $\supset$ & $>$ \\
\hline 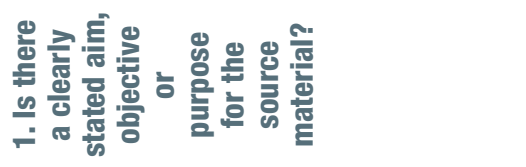 & $>$ & 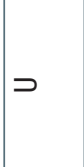 & $>$ & $>$ & $>$ & 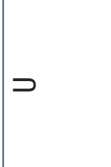 & $\supset$ & $>$ & $>$ & $>$ & $>$ \\
\hline 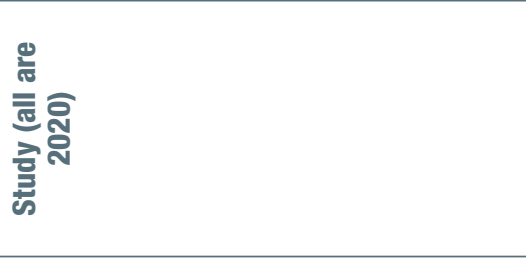 & 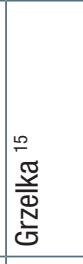 & 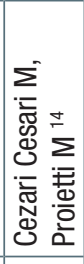 & $\begin{array}{l}= \\
\frac{\pi}{0} \\
\frac{0}{0} \\
\frac{0}{0} \\
\frac{0}{0}\end{array}$ & 哭 & 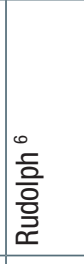 & 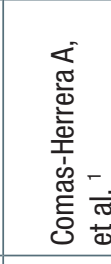 & 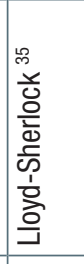 & 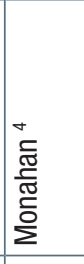 & 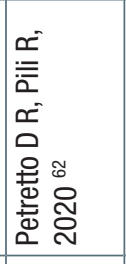 & 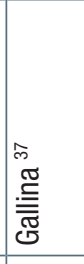 & 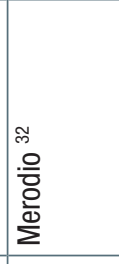 \\
\hline$z$ & - & $\sim$ & m & | & مـ & 0 & $\lambda$ & $\infty$ & 0 & 은 & $\mp$ \\
\hline
\end{tabular}




\begin{tabular}{|c|c|c|c|c|c|c|c|c|c|c|}
\hline 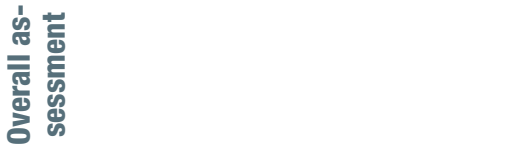 & 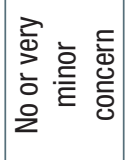 & 흘 & 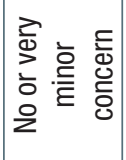 & 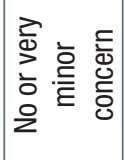 & 号 등 & 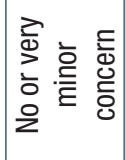 & 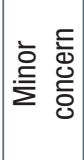 & 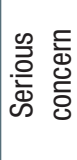 & 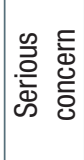 & 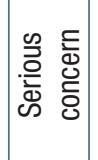 \\
\hline 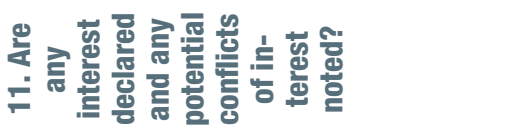 & $>$ & $>$ & $>$ & $>$ & $z$ & $>$ & $>$ & $>$ & $z$ & $z$ \\
\hline 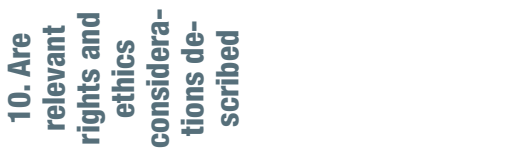 & $>$ & $\supset$ & $>$ & $>$ & $z$ & $\supset$ & $>$ & $>$ & $>$ & $>$ \\
\hline 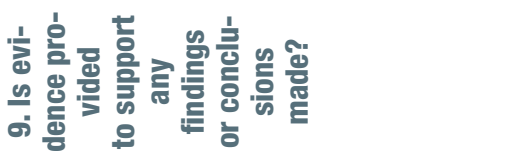 & $>$ & $>$ & $>$ & $>$ & $>$ & $>$ & $\supset$ & $z$ & $>$ & $>$ \\
\hline 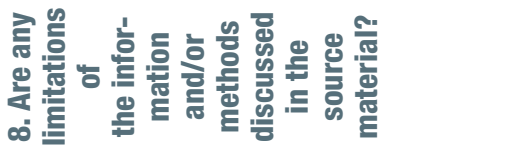 & $>$ & 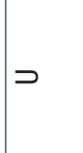 & $\supset$ & $>$ & $z$ & $\supset$ & $>$ & $z$ & $z$ & $\supset$ \\
\hline 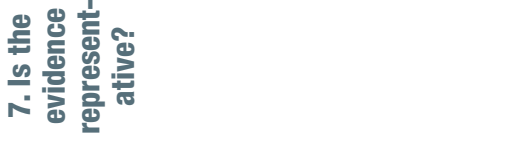 & $>$ & $\supset$ & $>$ & $\supset$ & $\supset$ & $>$ & $\supset$ & $z$ & $>$ & $>$ \\
\hline 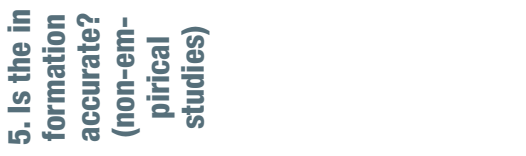 & $>$ & $>$ & $>$ & $>$ & $>$ & $>$ & $>$ & $\supset$ & $>$ & $>$ \\
\hline 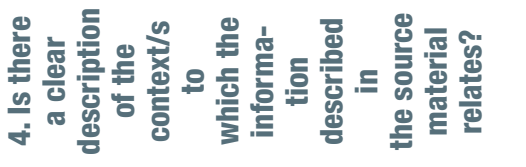 & $>$ & $\supset$ & $>$ & $>$ & $\supset$ & $>$ & $\supset$ & $>$ & $\supset$ & $>$ \\
\hline 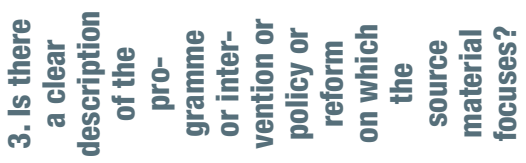 & $>$ & $>$ & $>$ & $>$ & $>$ & $>$ & $>$ & $>$ & $>$ & $>$ \\
\hline 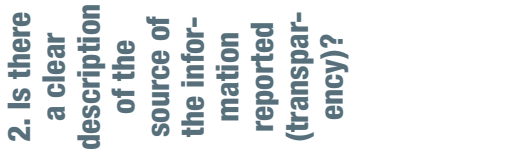 & $>$ & 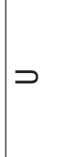 & $>$ & $>$ & $\supset$ & $>$ & 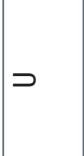 & $\supset$ & $>$ & $>$ \\
\hline 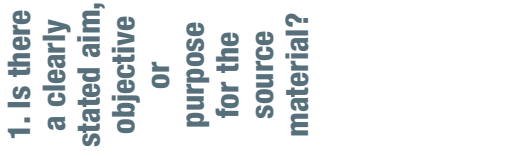 & $>$ & $>$ & $>$ & $>$ & $>$ & $>$ & $>$ & $>$ & $\supset$ & $>$ \\
\hline 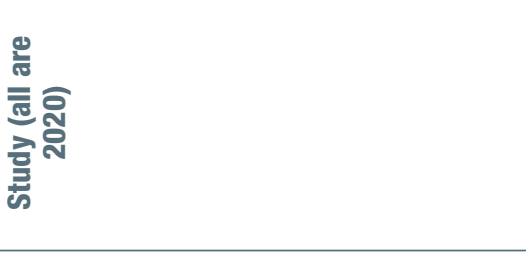 & 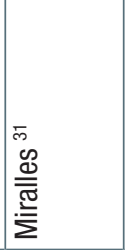 & 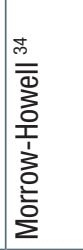 & 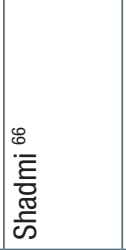 & 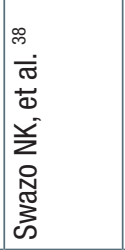 & 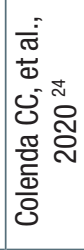 & 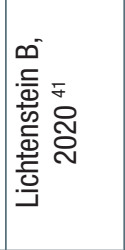 & 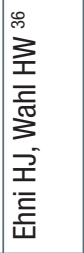 & 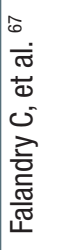 & 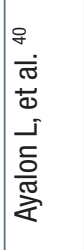 & 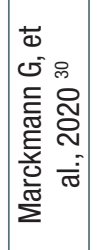 \\
\hline $\mathbf{z}$ & $\simeq$ & $\stackrel{m}{\sim}$ & $\nexists$ & $\stackrel{20}{2}$ & $\stackrel{\oplus}{\circ}$ & $\stackrel{\sim}{\circ}$ & $\stackrel{\infty}{-}$ & $\stackrel{\rho}{-}$ & నิ & $\bar{\sim}$ \\
\hline
\end{tabular}


Table II. Reviewed articles (author, country, summary of results).

\begin{tabular}{|c|c|c|c|}
\hline Goal & Country & Author & $\mathbf{N}$ \\
\hline $\begin{array}{l}\text { To study how Polish public perceive vulnerable populations during the } \\
\text { COVID-19 outbreak }\end{array}$ & Poland & Grzelka & 1 \\
\hline $\begin{array}{l}\text { To study ageism and decisions made during the COVID-19 outbreak despite } \\
\text { the limited resources at the height of the disease }\end{array}$ & Italy & Cesari M, Proietti M & 2 \\
\hline $\begin{array}{l}\text { To provide basic ethical guidelines to treat patients with suspected or } \\
\text { definitive diagnosis of coronavirus disease (COVID-19) and to address the } \\
\text { moral considerations inherent to caring for this patient population, especially } \\
\text { in the context of scarce resource allocation, imposition of restrictions to } \\
\text { individual freedoms, and de facto social distancing }\end{array}$ & $\begin{array}{l}\text { United States of } \\
\text { America }\end{array}$ & DePergola ${ }^{11}$ & 3 \\
\hline $\begin{array}{l}\text { Presenting a framework for rationing ventilators and critical care beds during } \\
\text { COVID- } 19 \text { pandemic }\end{array}$ & $\begin{array}{l}\text { United States of } \\
\text { America }\end{array}$ & White $^{9}$ & 4 \\
\hline $\begin{array}{l}\text { Reviewing emerging discriminatory issue and presenting evidence against } \\
\text { attempts to define "the COVID-19 Generation" as a new construct along } \\
\text { with conceptual, methodological and practical lines, with a specific focus on } \\
\text { identifying real dangers related to examining and potentially managing a new } \\
\text { generation related to this pandemic in media }\end{array}$ & Germany & Rudolph ${ }^{35}$ & 5 \\
\hline $\begin{array}{l}\text { Evaluating the effect of COVID-19 on care home residents and staff and } \\
\text { as new and updated information and data become available, summarizing } \\
\text { information from three types of sources: epidemiological studies, official } \\
\text { estimates and news reports }\end{array}$ & United Kingdom & Comas-Herrera $\mathrm{A}$, et al ${ }^{1}$ & 6 \\
\hline $\begin{array}{l}\text { Investigating impacts of COVID-19 on elderly in low- and middle-income } \\
\text { countries }\end{array}$ & United Kingdom & Lloyd-Sherlock & 7 \\
\hline $\begin{array}{l}\text { Investigating positive and negative responses toward older adults } \\
\text { during COVID-19 pandemic and the expected short- and long-term } \\
\text { consequences such as affecting beliefs about and treatment of older adults, } \\
\text { intergenerational relations, and individuals' mental and physical health. } \\
\text { The study addresses policy changes to health care (triaging, elder abuse), } \\
\text { employment (layoffs, retirement), and education about ageism }\end{array}$ & $\begin{array}{l}\text { United States of } \\
\text { America }\end{array}$ & Monahan & 8 \\
\hline Investigating the role of elderly in COVID-19 based on media & Italy & $\begin{array}{l}\text { Petretto DR, Pili R, } \\
2020^{62}\end{array}$ & 9 \\
\hline $\begin{array}{l}\text { To study decisions to offer interventions with limited availability of medical } \\
\text { resources }\end{array}$ & Italy & Gallina $^{37}$ & 10 \\
\hline $\begin{array}{l}\text { To collect evidence on hospital healthcare experiences of elderly infected } \\
\text { by COVID-19 and to analyze elements that have positively affected elderly } \\
\text { perceived health and well-being }\end{array}$ & Spain & Merodio & 11 \\
\hline $\begin{array}{l}\text { Summarizing actions, health policies and clinical guidelines adopted by six } \\
\text { European countries during the pandemic and assessing the effect of national } \\
\text { policies on reducing unfavorable effects of the COVID-19 pandemic in elderly }\end{array}$ & $\begin{array}{l}\text { Belgium, France, } \\
\text { Italy, Poland, Spain } \\
\text { and United Kingdom }\end{array}$ & Miralles & 12 \\
\hline $\begin{array}{l}\text { Recovering from the COVID-19 Pandemic in older adults with an focus on } \\
\text { increased comfort through technology and online platforms; stronger family } \\
\text { and intergenerational connections, renewed energy to combat social isolation; } \\
\text { more respect for self-care and time management; enhanced knowledge on } \\
\text { the importance of advance directives; and, potentially, increased interest } \\
\text { across disciplines to address the issues of aging society }\end{array}$ & $\begin{array}{l}\text { United States of } \\
\text { America }\end{array}$ & Morrow-Howell & 13 \\
\hline $\begin{array}{l}\text { 1. Exploring the challenges to health equity and describing some of the } \\
\text { approaches adopted by governments and local organizations in } 13 \text { countries } \\
\text { during Covid-19 pandemic } \\
\text { 2. Encouraging researchers to continue advancing global knowledge } \\
\text { on COVID-19 health equity related issues, through rigorous studies and } \\
\text { generation of a strong evidence based on new empirical studies in this field }\end{array}$ & $\begin{array}{c}\text { China, Brazil, } \\
\text { Thailand, Sub } \\
\text { Saharan Africa, } \\
\text { Nicaragua, Armenia, } \\
\text { India, Guatemala, } \\
\text { United States of } \\
\text { America (USA), Israel, } \\
\text { Australia, Colombia, } \\
\text { and Belgium }\end{array}$ & Shadmi & 14 \\
\hline
\end{tabular}


Table II. Reviewed articles (author, country, summary of results).

\begin{tabular}{|l|c|c|c|}
\hline Goal & country & Author & N \\
\hline $\begin{array}{l}\text { Evaluating the challenges faced by Bangladeshi physicians in treating and } \\
\text { refraining COVID-19 patients }\end{array}$ & Bangladesh & Swazo NK, et al. & 15 \\
\hline $\begin{array}{l}\text { Presenting this perspective as a way to enhance knowledge of people about } \\
\text { ageism concerning coronavirus disease (COVID-19) pandemic, } \\
\text { and acknowledging the extraordinary work that healthcare providers across } \\
\text { all disciplines, including geriatrics, are doing at the frontlines of care, and also } \\
\text { presenting these thoughts as advocates for older patients, their families, their } \\
\text { providers, and the broader community }\end{array}$ & Italy & Colenda CC, et al., 2020 & 16 \\
\hline $\begin{array}{l}\text { Comparing responses to COVID-19 control in Australia, the United Kingdom, } \\
\text { and the United States, 3 countries where public ageism erupted over the } \\
\text { social and economic costs of protecting older adults from COVID-19 }\end{array}$ & America & Lichtenstein B, 2020 41 & 17 \\
\hline $\begin{array}{l}\text { To provide suggestions on how to deal with beliefs and discriminatory } \\
\text { behaviors against older people in COVID-19 pandemic }\end{array}$ & Germany & Ehni HJ, Wahl HW & 18 \\
\hline $\begin{array}{l}\text { Investigating the challenges of management of elderly with cancer disease } \\
\text { during the COVID-19 pandemic such as increased risks of COVID-19 infection } \\
\text { and the temptations of ageism }\end{array}$ & France & Falandry C, et al. & 19 \\
\hline $\begin{array}{l}\text { To present some recommendations on how to navigate the current pandemic } \\
\text { in the world and confront ageism and intergenerational division }\end{array}$ & International & Ayalon L, et al. & 20 \\
\hline $\begin{array}{l}\text { To exame the decisions made on the allocation of intensive care resources } \\
\text { in the context of the COVID-19 pandemic and to provide some clinical and } \\
\text { ethical recommendations }\end{array}$ & Germany & Marckmann G, et al. & 21 \\
\hline
\end{tabular}

80 to 75 years, liberation of patients with a low chance of survival from the ventilator ${ }^{25}$, and decision on who survives and who dies $24,25,39,40$.

It was observed that age discrimination against old people influences decisions made in this regard ${ }^{40}$. Upon old people's arrival in the emergency and triage departments, the lowest priority was given to them to receive services and use medical facilities, which was due to the exclusion of them from treatment protocols and even lack of attention to the nursing home old people residents. This can be associated with some stereotypes in larger communities: old people do not need medical care, leading to an increase in their death rate and a negative impact on the family, friends, and society ${ }^{4}$. In this regard, the access of the nursing home old people residents to hospitals was limited, and old people were less referred to care centers after being discharged from the hospital ${ }^{31}$.

The priority of maintaining a maximum life and the random selection of patients with similar prognosis were among the problems of existing protocols ${ }^{37}$. In Spain, protocols were adjusted based on patients' age and disability, so that medical facilities and equipment such as ventilators, use of intensive care units, and home care services, were not provided to old people or disabled people, and the order of non-admission of people over 80 years of age to intensive care units was issued ${ }^{32}$. Lack of access to treatment for old people in the hospital and lack of equipment and staff in the nursing home were other measures leading to the increased mortality rate of old people in nursing homes ${ }^{7}$.

An emphasis was put on social distancing to prevent the spread of this disease in the development of protocols. Although the social distancing law is an essential measure to prevent the spread of COVID-19 disease, in the case of old people, this law reduces care for them and limits their access to health services ${ }^{4,37}$. Moreover, in social distancing laws, examples of vulnerability have not been specified; hence, governments have been accused of discriminatory behavior ${ }^{31}$. This law increased the isolation and loneliness of old people, leading to an increased risk of death, an increased risk of dementia, negative effects on physical and mental health such as anxiety, depression, readmission, increased heart disease, and exacerbated high-risk behaviors, including alcohol consumption and smoking in this age group ${ }^{4}$.

\section{FEELING OF INSIGNIFICANCE BY OLD PEOPLE THEMSELVES}

Induction of the feelings of insignificance in old people causes them not to seek treatment and their mental health is impaired; therefore, due to discriminatory behaviors, old people feel worthless and think that they impose an additional burden on their families and others ${ }^{4}$. Additionally, rejection of the treatment and healthcare services owing to lack of care resources and facilities as their task and internalization of the worthlessness of old people's lives ${ }^{36}$ are examples of the feeling of insignificance perceived by old people. This 
feeling finally results in the lack of mental health, lack of access to health services, financial problems, and an increase in the suicide rate among old people ${ }^{7}$. Despite the age discrimination against old people during the COVID-19 outbreak, some positive measures have been taken for them. For example, triaging in groups by experts to allocate the necessary treatment and care facilities, to communicate with a team of specialists, patients and families, to monitor the decisions taken to ensure justice, and to improve existing algorithms, has been observed. Furthermore, it has been emphasized on the transparency of the existing treatment and care guidelines on how to deal with old people ${ }^{4}$.

\section{DISCUSSION AND IMPLICATIONS}

The present study was an attempt to investigate the causes and types of discrimination against old people during the COVID-19 outbreak. After reviewing the included articles, it was found that most of the reports were from European countries and the United States. Many studies have been conducted on ageism in Western societies. Traxler (1980) investigated the roots of ageism among the old people in the Western world and explained its causes ${ }^{41}$. Studies have indicated an increase in negative stereotypes about old people in recent years ${ }^{42}$. However, the limitations of studies in other parts of the world, including ignoring ageism, should also be considered. Based on such a view, the health and life of old people become less important, and an anti-aging culture is promoted, leading to neglecting old people and causing diseases and complications in this group of people ${ }^{6}$. Anti-aging beliefs can be observed in the community behavior. Naming the disease under the titles of "the Boomer doomer", "the Boomer pruner" and "the Boomer remover" on social media is a sign of beliefs that young people are preferred to receive healthcare services during the COVID-19 outbreak ${ }^{3,34,35}$.

This culture is also seen among healthcare providers. The need to prioritize young people and triage old people, which was promoted by the community ${ }^{4}$, governments ${ }^{32}$, and the Rosenbaum Medical Association, confirms the cultural roots of age discrimination against old people. Research suggests a growing trend of antiaging attitudes among healthcare providers ${ }^{18,43}$. The mentioned facts reflect injustice in the delivery of health services, which is structurally institutionalized in societies and depends on factors, such as race, social class, and gender ${ }^{18}$. In this study, the age-related injustice was addressed. At times of an economic crisis, other types of discrimination are seen. During the COVID-19 outbreak, in addition to shortages in the area of care and equipment, there are economic problems that have led to not providing effective services to old people ${ }^{44}$. In a study, the financial burden of ageism on 8 important health services to old people was estimated as \$ 63 billion ${ }^{45}$. Certainly, it can be stated that ageism has led to more than 6 million cases of depression among old people, and prevention of it is very cost-effective economically ${ }^{18}$.

Although the shortage of care resources is inevitable in health crises, an anti-aging culture has been influential in developing COVID-19 care guidelines, so that old people are not directly or indirectly excluded from receiving the services. Thus, improvement of the resilience of the health system to deal with such a crisis is a priority for all public health systems ${ }^{46}$. One can mention the following as examples of discrimination against old people in the treatment process of this disease: age limitations in receiving care and treatment services, exclusion of patients with underlying diseases from the list of the service receiver, allocation of resources to people with a higher chance of survival ${ }^{4,25}$, preferring medical staff infected in allocating care resources ${ }^{13}$, giving a lower priority for old people in allocating care services and equipment ${ }^{4}$, elimination of old people from protocols to maintain the longest life years ${ }^{4,37}$, random selection of patients with similar prognosis for the delivery of medical services.

Previous studies also confirmed that delivery of healthcare services was based on the old people's age not their needs ${ }^{47}$. They also suggest that age is influential in making clinical decisions and determining the type of treatment ${ }^{48,49}$. In a meta-analysis of 400 articles conducted before the COVID-19 outbreak, $84.6 \%$ of studies reported the effect of age on the clinical decision-making ${ }^{4}$. The effects of age discrimination on the delivery of services, in addition to hospitals, have been increasingly reported in long-term nursing homes. For example, the following were observed in the protocols: lack of equipment of centers with personal protection facilities, lack of replacement of old people caregivers or caregivers' leave of caring old people, not referring old patients with physical dependence to hospitals by the nursing home, and not providing home care to old people.

Hence, more than half of the deaths caused by COVID-19 occurred in nursing homes ${ }^{4,7,32}$. Studies have shown that discrimination against old people has negative consequences like a higher risk of Alzheimer's disease for old people themselves ${ }^{50}$. The shortage of caregivers in nursing homes leads to deficiencies in care and reduces the quality of care ${ }^{51}$. One of the preventive measures during the COVID-19 outbreak was the implementation of the social distancing law. Although it is a good method to prevent the spread of this disease, it needs to be implemented intelligently in the case of old people. The old people, who depended on other people to meet the normal needs of their lives, were 
forgotten in this method, and their loneliness and isolation were intensified. Quarantine reduced old people's access to health services and care ${ }^{6,37}$. Ageism, at the societal level, includes stereotypes, prejudgments, and practical discrimination against old people, which in turn results in neglecting old people, their social separation, and loneliness ${ }^{52,53}$. Loneliness and social isolation are interrelated concepts but have different meanings. Isolation means reduced contact with people and the environment, while loneliness is a mental and stressful concept and occurs due to reduced social contacts ${ }^{3}$.

Loneliness is a major problem for old people ${ }^{54}$. Isolation and loneliness cause complications, such as anxiety, depression, cognitive disorders, heart disease, reduced quality of life, and death $3,54,55$. During the COVID-19 outbreak, due to the need for social distancing, the isolation of old people from society has increased and ageism, along with the feeling of insignificance among old people, has intensified the isolation and loneliness of old people $3,54,55$. Hence, it is recommended to pay more attention to the loneliness of old people during this period. Additionally, due to changes in the life style of people during the COVID-19 outbreak, there is a need to change the research attitude toward evaluating the answers, determining learned lessons, and developing the methods used to examine the loneliness and social isolation among old people ${ }^{56}$. The feeling of insignificance among old people during the COVID-19 outbreak and dealing with discriminatory behaviors caused problems, such as lack of follow-up care and mental health disorders ${ }^{4}$. The common discriminatory stereotypes in society are internalized by old people, and they actively distance themselves from being considered an old person so as not to be exposed to stereotypes ${ }^{57}$. Based on the stereotype embodiment theory, the effects of ageism on all aspects of health, including mental health, were identified and they included a decrease in self-efficacy, perceived control, and reduced meaning of life ${ }^{18}$. Old people's perception of aging affects their self-efficacy and consequently their physical performance, so that if they have a better feeling about aging, their self-efficacy will be higher ${ }^{58}$. Hence, old people think they are obliged to refuse to accept health services to save the lives of young people, as this feeling of worthlessness has been institutionalized in them ${ }^{36}$, even leading to complications like an increased suicide rate ${ }^{7}$. On the contrary, a positive perception of aging improves health-related behaviors that are beneficial to people at risk ${ }^{59}$ and if old people resist these negative stereotypes, symptoms, such as suicidal ideation and anxiety, will become reduced ${ }^{60}$. It appears that old people are a heterogeneous group in health, and this issue should be considered in the treatment of these patients. Age is an inappropriate variable and very poor guidance to consider it a criterion in the delivery of care and treatment services ${ }^{4}$. Calendar age should not be regarded as the primary criterion for determining access to medical care services ${ }^{32,40}$, and it is required to address old people's health needs and adopt a superindividual perspective in this regard ${ }^{30}$.

Moreover, providing psychological support for old people during this period ${ }^{61}$, prioritizing ethics over law ${ }^{37}$, and paying attention to the principle of equality in receiving health services declared by the World Health Organization ${ }^{32}$ should also be considered against discriminatory behavior during the COVID-19 outbreak to take effective steps to prevent more harm coming to this group of people. Some of the measures taken in this regard include triaging by a group of experts to allocate the necessary facilities for treatment and care, communicating with the specialist team, patient and family, monitoring the decisions taken to ensure justice, modifying existing algorithms ${ }^{25}$, ensuring transparency of guidelines ${ }^{4}$ and avoiding age cut-point for receiving services ${ }^{4,32,39}$. Public education regarding the aging process and the positive roles of old people in society creates negative stereotypes about old people ${ }^{62}$. It requires theoretical foundations. A comprehensive model in this regard refers to two basic points. The first is the importance of education in the aging process and the positive roles of old people to reduce the negative mentality in aging, and the second is to provide opportunities to contact with old people in the form of personal experiences that lead to development of opportunities for cooperation and sharing personal information ${ }^{63}$. Fortunately, positive attitudes have been reported more than negative attitudes among hospital staff in some studies ${ }^{33,64}$. Furthermore, the positive attitude of old people toward themselves has been effective in reducing the complications of COVID-19 ${ }^{39}$. Among the measures to protect old people during the COVID-19 outbreak period, one can mention protection laws for old people, such as presence of them at less busy times of day for shops, complete disinfection of places where old people are present, and delivering their needed goods at their homes. Although the social distancing law is useful for old people, its consequences must be considered ${ }^{4}$. Thus, ageism should be considered one of the social determinants of health and should be seriously addressed. Owing to discriminatory behaviors in the delivery of health services to old people, it is necessary for health policymakers to develop protocols related to the delivery of care in this group and enact protective laws in a way that the least harm comes to this vulnerable group. It is also recommended that healthcare staff be trained to provide services for old people. 


\section{CONCLUSIONS}

Given the global nature of the agism phenomenon, it is better to use the methods used in countries like Germany, to deal with crises related to this phenomenon. The number of deaths due to COVID-19 is not just numbers but the number of lives lost. The existence of anti-ageism laws is highly important in cases of humanitarian crises.

Educating children about the importance of the presence of old people in society and combating the discriminatory culture against old people will improve society's outlook on old people, especially their health. Therefore, at times of crisis, old people, like other highrisk groups, such as children and pregnant women, should be given special attention. In this regard, the training of health personnel is vital.

Preparing people for old age, particularly the middle age, will increase their self-confidence and awareness of the presence of the elderly in society and will prevent them from neglecting themselves.

\section{STUDY LIMITATIONS}

First, all available studies were descriptive, and this prevented accurate conclusions. Second, most of the studies were conducted in Western countries, and no information was available from less developed countries. Third, most reports of ageism during the COVID-19 outbreak were not officially available in scientific institutes and associations, and except for a few of them ${ }^{34,39,54,77}$; the remaining studies were the result of unofficial observations and reports. Moreover, protocols were preferably implemented secretly ${ }^{23}$.

\section{Ethical consideration}

This study was approved by Isfahan University of Medical Science ethics committee.

\section{Acknowledgement}

We respectfully thank Professor Ziba Farajzadegan for her guidance.

\section{Funding}

This work was supported by Isfahan University of Medical Sciences.

\section{Conflict of interest}

The Authors have no conflict of interest to declare.

\section{References}

1 Comas-Herrera A, Zalakain J, Lemmon E, et al. Mortality associated with COVID-19 outbreaks in care homes: early international evidence. International Long-Term Care Policy Network, 2020.
2 WHO Coronavirus (COVID-19) Dashboard. World Health Organization 2021 (https://covid19.who.int).

3 Brooke J, Jackson D. Older people and COVID-19: Isolation, risk and ageism. J Clin Nurs 2020;29:2044-2046. https://doi.org/10.1111/jocn.15274

4 Monahan C, McDonald J, Ashley L, et al. COVID-19 and ageism: how positive and negative responses impact older adults and society. Am Psychol 2020;75:887-896. https:// doi.org/10.1037/amp0000699

5 Rahimi M, Maracy MR, Shahraki RA. A survey of knowledge, attitude and practice of the older people about COVID-19 pandemic in Isfahan, Iran. Journal of Gerontology and Geriatrics 2020;68:204-211. https://doi. org/10.36150/2499-6564-253

6 Lloyd-Sherlock P, Ebrahim S, Geffen L, et al. Bearing the brunt of COVID-19: older people in low and middle income countries. BMJ 2020;368:m1052. https://doi. org/10.1136/bmj.m1052

7 Flett GL, Heisel MJ. Aging and feeling valued versus expendable during the COVID-19 pandemic and beyond: a review and commentary of why mattering is fundamental to the health and well-being of older adults. Int J Ment Health Addict 2020:1-27. https://doi.org/10.1007/ s11469-020-00339-4

8 Mahmoodi R, Hassanzadeh A, Rahimi M. Health literacy and its dimensions in elderly people in Farsan city, Iran. J Edu Health Promot 2021;10:362. https://doi.org/10.4103/ jehp.jehp_149_21

9 Fox MT, Persaud M, Maimets I, et al. Effectiveness of acute geriatric unit care using acute care for elders components: a systematic review and meta-analysis. J Am Geriatr Soc 2012;60:2237-2245. https://doi.org/10.1111/jgs.12028

10 Lachs MS, Williams CS, O'Brien S, et al. The mortality of elder mistreatment. JAMA 1998;280:428-432.

11 DePergola II PA. Ethical guidelines for the treatment of patients with suspected or confirmed novel coronavirus disease (COVID-19). J Health Ethics 2020;16:4. https:// doi.org/10.18785/ojhe.1601.04

12 Fraser S, Lagacé M, Bongué B, et al. Ageism and COVID-19: what does our society's response say about us? Age Ageing 2020;49:692-695. https://doi.org/10.1093/ ageing/afaa097

13 White DB, Lo B. A Framework for rationing ventilators and critical care beds during the COVID-19 pandemic. JAMA 2020;323:1773-1774. https://doi.org/10.1001/ jama.2020.5046

14 Cesari M, Proietti M. COVID-19 in Italy: ageism and decision making in a pandemic. J Am Med Directors Ass 2020;21:576-577. https://doi.org/10.1016/j. jamda.2020.03.025

15 Grzelka M. Attitudes toward vulnerable populations in the time of COVID-19: critical discourse analysis of Gazeta. PI Online Comment Sections. Society Register 2020;4:121132. https://doi.org/10.14746/sr.2020.4.2.09

16 Harper S. A chance to create a better world? J Popul Ageing 2020;13:281-283. https://doi.org/10.1007/ s12062-020-09295-2 
17 Jackson SE, Hackett RA, Steptoe A. Associations between age discrimination and health and wellbeing: cross-sectional and prospective analysis of the English longitudinal study of ageing. The Lancet Public Health 2019;4:e200e208. https://doi.org/10.1016/S2468-2667(19)30035-0

18 Chang E-S, Kannoth S, Levy S, et al. Global reach of ageism on older persons' health: a systematic review. PLoS One 2020;15:e0220857. https://doi.org/10.1371/journal. pone.0220857

19 Kydd A, Fleming A. Ageism and age discrimination in health care: fact or fiction? A narrative review of the literature. Maturitas 2015;81:432-438. https://doi.org/10.1016/j. maturitas.2015.05.002

20 Toygar I, Kardakovan A. Factors affecting the attitudes of nursing students toward ageism. Nursing Practice Today 2020;7:38-44. https://doi.org/10.1093/geronb/gbx056

21 Kagan SH, Melendez-Torres G. Ageism in nursing. J Nurs Manag 2015;23:644-650. https://doi.org/10.1111/ jonm. 12191

22 Rippon I, Kneale D, de Oliveira C, et al. Perceived age discrimination in older adults. Age Ageing 2014;43:379-386. https://doi.org/10.1093/ageing/aft146

${ }^{23}$ Bagenstos SR. May hospitals withhold ventilators from COVID-19 patients with pre-existing disabilities? Notes on the law and ethics of disability-based medical rationing. Notes on the law and ethics of disability-based medical rationing (March 24, 2020) 2020. https://doi.org/10.2139/ ssrn.3559926

24 Colenda CC, Reynolds CF, Applegate WB, et al. COVID-19 pandemic and ageism: a call for humanitarian care. J Am Geriatr Soc 2020;68:1627-1628. https://doi.org/10.1111/ jgs. 16663

25 Rosenbaum L. Facing COVID-19 in Italy - ethics, logistics, and therapeutics on the epidemic's front line. New Engl J Med 2020;382:1873-1875. https://doi.org/10.1056/ NEJMp2005492

${ }^{26}$ Utych SM, Fowler L. Age-based messaging strategies for communication about COVID-19. J Behav Public Administr 2020;3. https://doi.org/10.30636/jbpa.31.151

27 Levy B. Stereotype embodiment: a psychosocial approach to aging. Curr Direct Psychol Sci 2009;18:332-336. https://doi.org/10.1111/j.1467-8721.2009.01662.x

28 Conway A, Reszel J, Walker MC, et al. Obstetrical safety indicators for preventing hospital harms in low risk births: a scoping review protocol. BMJ Open 2020;10:e036203. https://doi.org/10.1136/bmjopen-2019-036203

29 Lewin S, Langlois E, Tuncalp Ö, et al. WEIRD (Ways of Evaluating Important and Relevant Data) tool Questions to guide assessment/critical appraisal of programme descriptions, implementation descriptions and other mainly descriptive types of evidence, 2019. (https://epoc. cochrane.org/sites/epoc.cochrane.org/files/public/uploads/Resources-for-authors2017/weird_tool.pdf).
30 Marckmann G, Neitzke G, Schildmann J, et al. Decisions on the allocation of intensive care resources in the context of the COVID-19 pandemic: clinical and ethical recommendations of DIVI, DGINA, DGAI, DGIIN, DGNI, DGP, DGP and AEM. Med Klin Intensivmed Notfmed 2020;115(Suppl 3):115-122. https://doi.org/10.1007/ s00063-020-00709-9

${ }_{31}$ Miralles O, Sanchez-Rodriguez D, Marco E, et al. Unmet needs, health policies, and actions during the COVID-19 pandemic: a report from six European countries. Eur Geriatr Med 2021;12:193-204. https://doi.org/10.1007/ s41999-020-00415-X

32 Merodio G, Ramis-Salas M, Valero D, et al. How much is one life worth? The right to equity healthcare for improving older patients' health infected by COVID-19. Sustainability 2020;12:6848. https://doi.org/10.3390/su12176848

${ }_{33}$ Maxfield M, Pituch KA. COVID-19 worry, mental health indicators, and preparedness for future care needs across the adult lifespan. Aging Ment Health 2021;25:1273-1280. https://doi.org/10.1080/13607863.2020.1828272

34 Morrow-Howell N, Galucia N, Swinford E. Recovering from the COVID-19 pandemic: a focus on older adults. J Aging Soc Pol 2020;32:526-535. https://doi.org/10.1080/08959 420.2020 .1759758

35 Rudolph CWZ. "The COVID-19 generation": a cautionary note. Work Aging Retir 2020. 10.1093/workar/waaa009 [Epub Ahead of Print]

36 Ehni HJ, Wahl HW. Six propositions against ageism in the COVID-19 pandemic. J Aging Soc Policy 2020;32:515525. https://doi.org/10.1080/08959420.2020.1770032

37 Gallina P, Ricci M, Pera M. COVID-19: decisions to offer interventions with limited availability should be decided based on chance of recovery. J Am Med Dir Assoc 2020;21:993994. https://doi.org/10.1016/j.jamda.2020.05.024

38 Swazo NK, Talukder MMH, Ahsan MK. A duty to treat? A right to refrain? Bangladeshi physicians in moral dilemma during COVID-19. Philos Ethics Humanit Med 2020;15:7. https://doi.org/10.1186/s13010-020-00091-6

39 Ayalon L. There is nothing new under the sun: ageism and intergenerational tension in the age of the COVID-19 outbreak. Int Psychogeriatr 2020:1-4. https://doi. org/10.1017/S1041610220000575

40 Lichtenstein B. From "Coffin Dodger" to "Boomer Remover:" outbreaks of ageism in three countries with divergent approaches to coronavirus control. J Gerontol B Psychol Sci Soc Sci 2021;76:e206-e212. https://doi.org/10.1093/ geronb/gbaa102

${ }^{41}$ Traxler AJ. Let's get gerontologized: developing a sensitivity to aging. Southern Illinois University at Edwardsville, 1980.

$42 \mathrm{Ng} \mathrm{R}$, Allore HG, Trentalange M, et al. Increasing negativity of age stereotypes across 200 years: evidence from a database of 400 million words. PLoS One 2015;10:e0117086. https://doi.org/10.1371/journal.pone.0117086 
43 Liu Y-E, Norman IJ, While AE. Nurses' attitudes towards older people: a systematic review. Int J Nurs Stud 2013;50:1271-1282. https://doi.org/10.1016/j. ijnurstu.2012.11.021

44 Krosch AR, Amodio DM. Economic scarcity alters the perception of race. Proceedings of the National Academy of Sciences 2014;111:9079-9084. https://doi.org/10.1073/ pnas. 1404448111

45 Levy BR, Slade MD, Chang E-S, et al. Ageism amplifies cost and prevalence of health conditions. Gerontologist 2020;60:174-181. https://doi.org/10.1093/geront/gny131

46 Di Gennaro F, Gualano G, Timelli L, et al. Increase in tuberculosis diagnostic delay during first wave of the COVID-19 pandemic: data from an Italian infectious disease referral hospital. Antibiotics 2021;10:272. https://doi.org/10.3390/ antibiotics 10030272

47 Madan AK, Aliabadi-Wahle S, Beech DJ. Age bias: a cause of underutilization of breast conservation treatment. J Canc Educ 2001;16:29-32. https://doi. org/10.1080/08858190109528720

48 Barnow S, Linden M, Lucht M, et al. Influence of age of patients who wish to die on treatment decisions by physicians and nurses. Am J Geriatr Psych 2004;12:258-264.

49 Votron L, D'Hoore W, Swine C, et al. The opinion of general practitioners on the treatment of prostate and breast cancer in elderly people: results of a survey based on clinical models. Clin Oncol 2004;16:474-478. https://doi. org/10.1016/j.clon.2004.06.012

50 Levy BR, Ferrucci L, Zonderman AB, et al. A culture-brain link: negative age stereotypes predict Alzheimer's disease biomarkers. Psychol Aging 2016;31:82. https://doi. org/10.1037/pag0000062

51 Rahimi M, Fadayevatan R, Abedi H. Care instability in nursing homes; a qualitative study. Iran Red Crescent Med J 2017;1(Suppl 1):628-629. https://doi.org/10.5812/ ircmj.21515

52 Shiovitz-Ezra S, Shemesh J, McDonnell M. Pathways from ageism to loneliness. In: contemporary perspectives on ageism. New York, NY: Springer 2018, pp. 131-147.

53 Swift HJ, Abrams D, Lamont RA, et al. The risks of ageism model: how ageism and negative attitudes toward age can be a barrier to active aging. Soc Issues Pol Rev 2017;11. https://doi.org/10.1111/sipr.12031

54 Dykstra PA. Older adult loneliness: myths and realities. Eur J Ageing 2009;6:91. https://doi.org/10.1007/ s10433-009-0110-3
55 Barth J, Schneider S, Von Känel R. Lack of social support in the etiology and the prognosis of coronary heart disease: a systematic review and meta-analysis. Psychosom Med 2010;72:229-238. https://doi.org/10.1097/ PSY.0b013e3181d01611

56 Berg-Weger M, Morley J. Loneliness and social isolation in older adults during the COVID-19 pandemic: implications for gerontological social work. New York, NY: Springer 2020. https://doi.org/10.1007/s12603-020-1366-8

57 Van der Horst M. Internalised ageism and self-exclusion: does feeling old and health pessimism make individuals want to retire early? Soc Inclusion 2019;7:27-43. https:// doi.org/10.17645/si.v7i3.1865

58 Tovel H, Carmel S, Raveis VH. Relationships among selfperception of aging, physical functioning, and self-efficacy in late life. J Gerontol Series B 2019;74:212-221. https:// doi.org/10.1093/geronb/gbx056. https://doi.org/10.1093/ geronb/gbx056

59 Klusmann V, Sproesser G, Wolff JK, et al. Positive selfperceptions of aging promote healthy eating behavior across the life span via social-cognitive processes. J Gerontol Series B 2019;74:735-744. https://doi.org/10.1093/ geronb/gbx139

60 Levy BR, Pilver CE, Pietrzak RH. Lower prevalence of psychiatric conditions when negative age stereotypes are resisted. Soc Sci Med 2014;119:170-174. https://doi. org/10.1016/j.socscimed.2014.06.046

61 Petretto DR, Pili R. Ageing and COVID-19: what is the role for elderly people? Geriatrics 2020;5:4. https://doi. org/10.3390/geriatrics5020025

62 Lytle A, Macdonald J, Apriceno M, et al. Reducing ageism with brief videos about aging education, ageism, and intergenerational contact. Gerontologist 2021;61:1164-1168. https://doi.org/10.1093/geront/gnaa167

63 Levy SR. Toward reducing ageism: PEACE (positive education about aging and contact experiences) model. Gerontologist 2018;58:226-232. https://doi.org/10.1093/ geront/gnw116

64 ŞİMŞEK H, Bahadir H, Bilgin AC. Physicians'attitudes towards the elderly: ageism in a university hospital in Turkey. Türk Geriatri Dergisi 2019;22

65 Shadmi E, Chen Y, Dourado I, et al. Health equity and COVID-19: global perspectives. Int J Equity Health 2020;19:104. https://doi.org/10.1186/s12939-020-01218-z

66 Falandry C, Filteau C, Ravot C, et al. Challenges with the management of older patients with cancer during the COVID-19 pandemic. J Geriatr Oncol 2020;11:747-749. https://doi.org/10.1016/j.jgo.2020.03.020 


\section{SUPPLEMENTARY MATERIAL}

\begin{tabular}{|c|c|c|c|}
\hline Section/topic & \# & Checklist item & $\begin{array}{l}\text { Reported } \\
\text { on page \# }\end{array}$ \\
\hline \multicolumn{4}{|l|}{ TITLE } \\
\hline Title & 1 & Identify the report as a systematic review, meta-analysis, or both. & \\
\hline \multicolumn{4}{|l|}{ ABSTRACT } \\
\hline Structured summary & 2 & $\begin{array}{l}\text { Provide a structured summary including, as applicable: background; } \\
\text { objectives; data sources; study eligibility criteria, participants, and } \\
\text { interventions; study appraisal and synthesis methods; results; limitations; } \\
\text { conclusions and implications of key findings; systematic review registration } \\
\text { number. }\end{array}$ & \\
\hline \multicolumn{4}{|l|}{ INTRODUCTION } \\
\hline Rationale & 3 & Describe the rationale for the review in the context of what is already known. & \\
\hline Objectives & 4 & $\begin{array}{l}\text { Provide an explicit statement of questions being addressed with reference } \\
\text { to participants, interventions, comparisons, outcomes, and study design } \\
\text { (PICOS). }\end{array}$ & \\
\hline \multicolumn{4}{|c|}{ 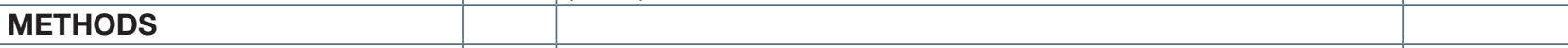 } \\
\hline Protocol and registration & 5 & $\begin{array}{l}\text { Indicate if a review protocol exists, if and where it can be accessed (e.g., } \\
\text { Web address), and, if available, provide registration information including } \\
\text { registration number. }\end{array}$ & \\
\hline Eligibility criteria & 6 & $\begin{array}{l}\text { Specify study characteristics (e.g., PICOS, length of follow-up) and report } \\
\text { characteristics (e.g., years considered, language, publication status) used as } \\
\text { criteria for eligibility, giving rationale. }\end{array}$ & \\
\hline Information sources & 7 & $\begin{array}{l}\text { Describe all information sources (e.g., databases with dates of coverage, } \\
\text { contact with study authors to identify additional studies) in the search and } \\
\text { date last searched. }\end{array}$ & \\
\hline Search & 8 & $\begin{array}{l}\text { Present full electronic search strategy for at least one database, including } \\
\text { any limits used, such that it could be repeated. }\end{array}$ & \\
\hline Study selection & 9 & $\begin{array}{l}\text { State the process for selecting studies (i.e., screening, eligibility, included in } \\
\text { systematic review, and, if applicable, included in the meta-analysis). }\end{array}$ & \\
\hline Data collection process & 10 & $\begin{array}{l}\text { Describe method of data extraction from reports (e.g., piloted forms, } \\
\text { independently, in duplicate) and any processes for obtaining and confirming } \\
\text { data from investigators. }\end{array}$ & \\
\hline Data items & 11 & $\begin{array}{l}\text { List and define all variables for which data were sought (e.g., PICOS, funding } \\
\text { sources) and any assumptions and simplifications made. }\end{array}$ & \\
\hline Risk of bias in individual studies & 12 & $\begin{array}{l}\text { Describe methods used for assessing risk of bias of individual studies } \\
\text { (including specification of whether this was done at the study or outcome } \\
\text { level), and how this information is to be used in any data synthesis. }\end{array}$ & \\
\hline Summary measures & 13 & State the principal summary measures (e.g., risk ratio, difference in means). & \\
\hline Synthesis of results & 14 & $\begin{array}{l}\text { Describe the methods of handling data and combining results of studies, if } \\
\text { done, including measures of consistency }\left(e . g ., l^{2}\right) \text { for each meta-analysis. }\end{array}$ & \\
\hline
\end{tabular}




\begin{tabular}{|c|c|c|c|}
\hline Section/topic & $\#$ & Checklist item & $\begin{array}{l}\text { Reported on } \\
\text { page \# }\end{array}$ \\
\hline Risk of bias across studies & 15 & $\begin{array}{l}\text { Specify any assessment of risk of bias that may affect the cumulative } \\
\text { evidence (e.g., publication bias, selective reporting within studies). }\end{array}$ & \\
\hline Additional analyses & 16 & $\begin{array}{l}\text { Describe methods of additional analyses (e.g., sensitivity or subgroup } \\
\text { analyses, meta-regression), if done, indicating which were pre-specified. }\end{array}$ & \\
\hline \multicolumn{4}{|c|}{ 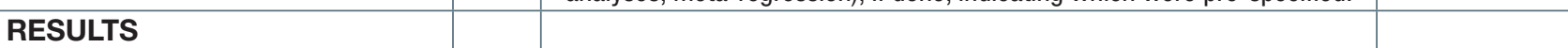 } \\
\hline Study selection & 17 & $\begin{array}{c}\text { Give numbers of studies screened, assessed for eligibility, and included in } \\
\text { the review, with reasons for exclusions at each stage, ideally with a flow } \\
\text { diagram. }\end{array}$ & \\
\hline Study characteristics & 18 & $\begin{array}{l}\text { For each study, present characteristics for which data were extracted (e.g., } \\
\text { study size, PICOS, follow-up period) and provide the citations. }\end{array}$ & \\
\hline Risk of bias within studies & 19 & $\begin{array}{c}\text { Present data on risk of bias of each study and, if available, any outcome } \\
\text { level assessment (see item 12). }\end{array}$ & \\
\hline Results of individual studies & 20 & $\begin{array}{l}\text { For all outcomes considered (benefits or harms), present, for each study: } \\
\text { (a) simple summary data for each intervention group (b) effect estimates } \\
\text { and confidence intervals, ideally with a forest plot. }\end{array}$ & \\
\hline Synthesis of results & 21 & $\begin{array}{l}\text { Present results of each meta-analysis done, including confidence intervals } \\
\text { and measures of consistency. }\end{array}$ & \\
\hline Risk of bias across studies & 22 & Present results of any assessment of risk of bias across studies (see Item 15). & \\
\hline Additional analysis & 23 & $\begin{array}{c}\text { Give results of additional analyses, if done (e.g., sensitivity or subgroup } \\
\text { analyses, meta-regression [see Item 16]). }\end{array}$ & \\
\hline \multicolumn{4}{|l|}{ DISCUSSION } \\
\hline Summary of evidence & 24 & $\begin{array}{c}\text { Summarize the main findings including the strength of evidence for each } \\
\text { main outcome; consider their relevance to key groups (e.g., healthcare } \\
\text { providers, users, and policy makers). }\end{array}$ & \\
\hline Limitations & 25 & $\begin{array}{l}\text { Discuss limitations at study and outcome level (e.g., risk of bias), and at } \\
\text { review-level (e.g., incomplete retrieval of identified research, reporting } \\
\text { bias). }\end{array}$ & \\
\hline Conclusions & 26 & $\begin{array}{l}\text { Provide a general interpretation of the results in the context of other } \\
\text { evidence, and implications for future research. }\end{array}$ & \\
\hline \multicolumn{4}{|l|}{ FUNDING } \\
\hline Funding & 27 & $\begin{array}{l}\text { Describe sources of funding for the systematic review and other support } \\
\text { (e.g., supply of data); role of funders for the systematic review. }\end{array}$ & \\
\hline
\end{tabular}

From: Moher D, Liberati A, Tetzlaff J, et al.; the PRISMA Group. Preferred reporting items for systematic reviews and meta-analyses: the PRISMA Statement. PLoS Med 2009;6:e1000097. https://doi.org/10.1371/journal.pmed1000097 (For more information, visit: www.prisma-statement.org). 